Egypt. J. of Appl. Sci., 35 (12) 2020

\title{
EFFECT OF CORN SILK, PUMPKIN SEEDS, AND CREATINE ON OXIDATIVE STRESS OF MALE EXERCISED RATS
}

Naeem M. Rabeh ; Mohammed H. Haggag and Asmaa Z. Mohammed

Nutrition and Food Sci. Dept, Faculty of Home Economics, Helwan Univ., Cairo-Egypt Key Words: Corn silk, Pumpkin seeds, creatine supplementation, creatine kinase, lactate dehydrogenase, treadmill, oxidative stress.

\begin{abstract}
The present study was conducted to investigate the effect of corn silk, pumpkin seeds and creatine supplementation on oxidative stress biomarker as well as liver function and glycogen content of adult male exercised rats. Fifty male albino rats were fed on basal diet for one week for adaptation. During the adaptive week all rats (except negative control group) were exposed to day after day forced treadmill running exercise for 10 min. Rats were divided into two main groups, the first main group ( $\mathrm{n}=10$ rats) was fed on basal diet only and served as negative control group. The second main group (exercised rats) were divided into 4 subgroups (10 rats each) as followed:-Subgroup 1: were fed on basal diet and had run for 10, 15, 20 and 25minutes (15 days for each time period), respectively and served as positive control group. The Subgroups (2-4) as the same of positive control subgroup and were fed on basal diet supplemented with $4 \%$ corn silk powder, $4 \%$ pumpkin seeds powder and $4 \%$ creatine powder, respectively. At the end of the experimental period (60 day), 5 rats of each subgroup were exposed to the exhausting treadmill test and the run time was recorded, then all experimental rats were scarified. Findings of these study prove that corn silk and pumpkin seeds were a good source of flavonoid which help to scavenge the oxidative stress substances, and improve liver functions, while creatine recorded the largest glycogen quantity in gastrocnemius muscles among supplemented groups, but it causing an elevation ammonia, and AST levels on the group which exposure to exhaustive time test. It could be recommended that corn silk and pumpkin seeds have the ability to eliminate physical fatigue and prolong the training period without fatigue
\end{abstract}

\section{INTRODUCTION}

Biomarker discovery and validation is a critical aim of the medical and scientific community. Research into exercise and diet-related biomarkers aims to improve health, performance, and recovery in military personnel, athletes, and lay

Persons. Exercise physiology research has identified individual biomarkers for assessing health, performance, and recovery during 
exercise training. However, there are few recommendations for biomarker panels for tracking changes in individuals participating in physical activity and exercise training programs (lee $\boldsymbol{e t}$ al .,2017). The diversity of nutrients or compounds from food factors or medical herbs could be investigated for their possible effect on exercise physiology and for understanding the different bioactivities that could be used for health promotion (Ching et al., 2015). Physical activity modifies the balance between oxidative stress and antioxidant defense mechanisms. For both athletes and fitness enthusiasts, the combination of regular physical activity and antioxidant supplement may have important restorative effects on the body's oxidation reduction or redox balance (Araújo et al., 2013).

Corn silk (Maydis stigma) is a waste material from corn cultivation, available in abundance, and possesses antioxidant, anti-fatigue, antitumor and anti-fungal activities (Ebrahimzadeh et al., 2009 and $\mathrm{Hu}$ et al., 2010).

The seeds of pumpkin are generally considered to be agroindustrial wastes and discarded. In some parts of the world, the seeds are consumed raw, roasted or cooked, but only at the domestic scale. With the discovery of their richness in protein, fibers, minerals, polyunsaturated fatty acids and phytosterols, they are being regarded valuable for the food industry. Also, their beneficial effects on blood glucose level, immunity, and cholesterol, liver, prostate gland, bladder, depression, learning disabilities and parasite inhibition are being validated (Patel, 2013). Dietary supplementation with creatine $(\mathrm{CrS})$ is popular in the sports and fitness industry. While certain mechanisms of action involved in improved physical exercise performance with $\mathrm{CrS}$ have been established (Gama, 2011 ).

Therefore, the aim of the study was to investigate the oxidative stress effect of corn silk, pumpkin seeds and creatine supplementation on adult male trained rats and their exercise performance.

\section{Materials:}

\section{MATERIALS AND METHODS}

Corn silk and Pumpkin seeds were purchased from Field Crops Research Institute, Ministry of Agriculture Giza, Egypt. Chemicals: Creatine powder, casein, vitamin mixture, mineral mixture and cellulose were purchased from El-Gomhoria Pharmaceutical Company, Cairo, Egypt. Rats: fifty young adult male albino rats of Sprague- Dawely Strain, weighting (150 $\pm 5 \mathrm{~g})$ were obtained from Animal House Colony of Vacsera, Helwan, Egypt. Kits for blood analysis were purchased from Gama Trade Company for Chemicals, Cairo, Egypt. The Treadmill was purchased from Sports Equipment Store, Cairo, Egypt (YY-T900D Luxury electronic treadmill, Motor power 3,0HP Quality in Taiwan with 
an adjustable speed $(0,8-14.8 \mathrm{Km} / \mathrm{h})$, Running surface $1230 * 430 \mathrm{~mm}$, and expand dimensions $1620^{*} 700^{*} 1200 \mathrm{~mm}$ enabling forced exercise training and accurate testing of fatigue in rats.

\section{Methods:}

Preparation of Dried Plants:-Fresh corn silk and pumpkin seeds were washed by using tap water and were dried using solar energy at the National Research Centre, Giza, Egypt in the sun at $50^{\circ} \mathrm{C}$ for two days then grounded to get a fine powder .The mild temperature $\left(45-55^{\circ} \mathrm{C}\right)$ enable the dried product to retain its nutrients as described by (Andritsos et al., 2003).

Active components (phenolic-flavonoids) and antioxidant activity of corn silk and pumpkin seeds were determined chemically according to the method described by (Brand-Williams et al., 1995)

Experimental Design:-

This study was carried out at the Animal House of Home Economic Faculty, Helwan University. Fifty male albino rats, were housed in well aerated cages under hygienic condition and were fed on basal diet for one week for adaptation. During the adaptive week all rats (except negative control group) were exposed to day after day forced treadmill running exercise for 10 min by using treadmill according to the method of (Davis, 2009).

Rats were divided into two main groups, the first main group $(n=10$ rats) were fed on basal diet only and served as negative control group. The second main group (exercised rats) were divided into 4 subgroups (10 rats each) as followed:- Subgroup 1: were fed on basal diet and will be run for 10, 15, 20 and 25 minutes (15 days for each time period), respectively and served as positive control group. The Subgroups (2-4) as the same of positive control subgroup and were fed on basal diet supplemented with $4 \%$ corn silk powder, $4 \%$ pumpkin seeds powder and $4 \%$ creatine powder, respectively.

The exhausting time protocol:

At the end of the experimental period (60 day), 5 rats of each subgroup were exposed to the exhausting treadmill test and the run time was recorded, then all experimental rats were scarified. Blood samples were collected and centrifuged to obtained serum which was used for the biochemical analysis. Liver and gastrocnemius muscle were collected from each rat to determine glycogen content (Banchroft et al., 1996)

Biochemical analysis of serum:

Serum samples were used for the determination of glucose described by (Trinder, 1969 and Weissman and Klein, 1958), creatine kinase (Tietz, 1976), lactate dehydrogenase (Vassault $\boldsymbol{e t}$ al., 1986), Aspartate aminotransferase (AST) (Schumann et al., 2002), Alanine aminotransferase (ALT) was determined in serum according to 
(Sherwin, 1984)., Serum malondialdehyde (MDA) was determined by the method of (Ohkawa et al., 1979), Serum Glutathion-s-trasferase was determined by the method of (Habig et al., 1974).

\section{Statistical analysis:-}

The results was evaluated by statistically analyzed using computerized program SPSS results were expressed as mean \pm SD .differences among groups were analyzed of analysis of variance (ANOVA) using Duncan's test .A $\mathrm{p}<0.05$ was considered statistically according to (Sendecor and Cochran, 1986)

\section{RESULTS}

The total phenolic content of corn silk and pumpkin seeds are presented in Table (1). The results indicate that corn silk contained mild amount of myricetin acid ,benzoic acid, Salicylic acid, Neringein , Kampherol and mean value was $16.79,23.84,34.75,61.87,75.57 \mathrm{mg} /$ $\mathrm{kg}$ respectively. The Ellagic recorded the largest amount of phenolic content in corn silk with mean value $417.10 \mathrm{mg} / \mathrm{kg}$. On the other hand, pumpkin seed contained mild amount of Chlorogenic, Vanillin, Caffeine, benzoic acid, and Neringein with mean values 7.34, 8.12, 10.167, 13.47, and $22.88 \mathrm{mg} / \mathrm{kg}$ respectively. The largest amount of phenolic contents in pumpkin seeds was Ellagic and Catechol which recorded 71.91 and $76.84 \mathrm{mg} / \mathrm{kg}$ respectively.

Table (1): Corn silk and pumpkin seeds total phenolic content

\begin{tabular}{|c|c|c|}
\hline Phenolic Compounds & Corn Silk(mg / kg) & Pumpkin seed(mg / kg) \\
\hline Syringic acid & 1.49 & 1.04 \\
\hline Vanillic acid & 2.06 & 8.12 \\
\hline p- Coumaric acid & 2.25 & 1.52 \\
\hline Quercetin & 2.74 & -- \\
\hline Cinnamic acid & 3.63 & -- \\
\hline Rutin & 4.13 & -- \\
\hline Chlorogenic & 4.30 & 7.34 \\
\hline Ferulic acid & 4.82 & -- \\
\hline Caffeic acid & 5.02 & 2.29 \\
\hline Caffeine & 5.15 & 10.16 \\
\hline Myricetin acid & 16.80 & -- \\
\hline Benzoic acid & 23.85 & 13.47 \\
\hline Salicylic acid & 34.75 & 5.19 \\
\hline Neringein & 61.88 & 22.88 \\
\hline Kampherol & 75.58 & 1.93 \\
\hline Ellagic & 417.10 & 71.91 \\
\hline Quinol & -- & 1.12 \\
\hline Gallic acid & -- & 1.72 \\
\hline Pyrogallol & -- & 1.78 \\
\hline Catechol & -- & 76.84 \\
\hline
\end{tabular}


The data in table (2) shown the result of radical scavenging activity for corn silk and pumpkin seeds which recorded high antioxidant activity $99.68 \%$ at $5 \%$ concentration compared to corn silk which recorded 84.07 at $5 \%$ concentration.

Table (2): The Antioxidant activity of corn silk and pumpkin seed

\begin{tabular}{|l|c|c|c|c|}
\hline \multirow{2}{*}{ SN } & \multicolumn{4}{|c|}{ \% DPPH Radical-Scavenging Activity } \\
\cline { 2 - 5 } & $\mathbf{0 . 5 \%}$ & $\mathbf{1 . 0 \%}$ & $\mathbf{2 . 5 \%}$ & $\mathbf{5 \%}$ \\
\hline Corn Silk & $\mathbf{2 0 . 2 0}$ & $\mathbf{4 1 . 0 2}$ & $\mathbf{6 0 . 3 3}$ & $\mathbf{8 4 . 0 7}$ \\
\hline Pumpkin Seed & $\mathbf{3 1 . 7 9}$ & $\mathbf{4 6 . 5 3}$ & $\mathbf{8 8 . 5 0}$ & $\mathbf{9 9 . 6 8}$ \\
\hline
\end{tabular}

Table (3) recorded the effect of corn silk, pumpkin seeds, and creatine on FI, BWG, and FER in male rats which exposure to exhaustive test according to the experimental training treadmill protocol. Results indicate that positive control group which fed on basal diet throughout the experiment and was trained day after day for (60) days non significantly increased on FI level compared to (-ve) control group. Corn silk and creatine groups significantly increased FI compared to +ve group, otherwise pumpkin seeds group non significantly changed FI compared to ( +ve ) group. The highest feed intake was recorded at the creatine group. Rats in +ve control group had significant decrease $(\mathrm{P}<0.05)$ in $\mathrm{BWG}$ compared to $-\mathrm{ve}$ control group. Corn silk group and pumpkin group significantly decreased BWG compared to (+ve) control, on the other side, creatine group significantly increased BWG compared to (+ve) group and recorded the best group findings. Regarding to FER of rats in +ve control group was significantly decreased compared to -ve control group. Corn silk and pumpkin seeds significantly decreased FER compared to +ve control group, inversely creatine group was significantly increased FER compared to +ve control group. The best result in FER of all tested group was creatine group.

Table (3):Effect of corn Silk, pumpkin seed and creatine on BWG, FI and

FER of rats exposure to exhaustive test

\begin{tabular}{|c|c|c|c|c|}
\hline \multicolumn{2}{|c|}{$\begin{array}{l}\text { Parameters } \\
\text { Groups }\end{array}$} & FI g/day & BWG g & FER \\
\hline 1 & $(-v e)$ & $19.68 \pm 1.16^{c}$ & $62.25 \pm 2.99^{b}$ & $0.05 \pm 0.001^{a}$ \\
\hline 2 & (+ve) & $23.59 \pm 0.54^{c}$ & $33.00 \pm 2.88^{c}$ & $0.02 \pm 0.002^{b}$ \\
\hline 3 & Corn Silk & $26.99 \pm 1.17^{b}$ & $-56.00 \pm 2.54^{\mathrm{e}}$ & $-0.03 \pm 0.0011^{d}$ \\
\hline 4 & pumpkin & $20.00 \pm 0.88^{c}$ & $-14.50 \pm 1.58^{d}$ & $-0.01 \pm 0.001^{c}$ \\
\hline 5 & Creatine & $28.03 \pm 0.47^{a}$ & $72.75 \pm 2.21^{\mathrm{a}}$ & $0.04 \pm 0.001^{a}$ \\
\hline
\end{tabular}

All value represented as mean $\pm \mathrm{SD}$.

Means with different superscript are significantly different $(p<0.05)$

Table (4) illustrated the effect of corn silk, pumpkin seeds, and creatine on, FI, BWG, and FER in male rats which non exposure to exhaustive test (the end of experiment) in the experimental training 
treadmill protocol. Positive control group which fed on basel diet while not exposure at the end of experiment to exhaustive treadmill test had significant increase in FI amount compared to (-ve) group. All tested groups had significant decrease in FI compared to +ve control group. Rats in + ve control group had significant decrease in BWG compared to -ve control group. Pumpkin seeds and corn silk group significantly decreased $(\mathrm{P}<0.05)$ BWG compared to +ve control group, however creatine group significantly increased compared to +ve control group. The best findings in all test groups was creatine group. Positive control group showed significant decreased in FER compared to -ve control group. Pumpkin seeds and corn silk significant decreased FER compared to +ve control group on the opposite creatine group significantly increased compared to +ve control group and the best result from all tested group was creatine.

Table (4): Effect of corn Silk, pumpkin seed and creatine on BWG, FI and FER of rats non exposure to exhaustive male rats

\begin{tabular}{|c|c|c|c|c|}
\hline \multicolumn{2}{|c|}{$\begin{array}{l}\text { Parameters } \\
\text { Groups }\end{array}$} & FI g/day & BWG g & FER \\
\hline 1 & $(-\mathrm{ve})$ & $19.68 \pm 1.16^{b}$ & $62.25 \pm 2.99^{b}$ & $0.05 \pm \mathbf{0 . 0 1}^{\mathrm{b}}$ \\
\hline 2 & (+ve) & $22.25 \pm 1.26^{\mathrm{a}}$ & $24.75 \pm 2.50^{c}$ & $0.02 \pm 0.003^{c}$ \\
\hline 3 & corn Silk & $20.50 \pm 2.69^{b}$ & $-11.20 \pm 0.69^{d}$ & $-0.01 \pm 0.03^{d}$ \\
\hline 4 & Pumpkin & $20.63 \pm 2.18^{b}$ & $-08.00 \pm 0.06^{\mathrm{a}}$ & $-0.007 \pm 0.004^{a}$ \\
\hline 5 & Creatine & $20.83 \pm 2.34^{b}$ & $59.00 \pm 4.81^{b}$ & $0.05 \pm 0.001^{b}$ \\
\hline
\end{tabular}

All value represented as mean \pm SD.

Means with different superscript are significantly different $(p<0.05)$.

As shown in Table (5), the effect of corn silk, pumpkin seed and creatine on AST, which illustrated significant increase in (+ve) control group compared to (-ve) control group. Rats fed on corn silk non significantly decrease AST compared to (+ve) control group. Whereas, rats fed on pumpkin seeds and creatine recorded significant increase in AST level compared to (+ve) control group and. Corn silk group marked as the best group among all tested group. The concentration of ALT for (+ve) control group had significant decrease compared to (-ve) control group. Rats fed on corn silk had non-significant decrease compared to (+ve) control group. While rats which fed on pumpkin seeds and creatine noticed significant increase compared to (+ve) control group. Corn silk group recorded best findings among all tested group. Results indicate that positive control group had significant increase in ammonia level compared with (-ve) control group. While rats which fed on corn silk and pumpkin seeds were significantly decreased compared to (+ve) control group. Creatine group recorded significant increase among all tested group. 
Table (5): Effect of Corn Silk, Pumpkin Seed and Creatine on liver functions and ammonia Level on rats exposure to exhaustive time test

\begin{tabular}{|c|c|c|c|c|}
\hline \multicolumn{2}{|c|}{$\begin{array}{ll}\text { Groups } & \text { Parameters } \\
\end{array}$} & $\begin{array}{l}\text { AST } \\
\mathbf{u} / \mathbf{l}\end{array}$ & $\begin{array}{c}\text { ALT } \\
\mathbf{u} / \mathbf{l}\end{array}$ & $\begin{array}{c}\text { Ammonia } \\
\mu \mathrm{g} / \mathrm{dl}\end{array}$ \\
\hline 1 & $(-\mathrm{ve})$ & $122.00 \pm 2.83^{d}$ & $41.50 \pm 3.00^{b}$ & $73.00 \pm 10.61^{c}$ \\
\hline 2 & (+ve) & $128.20 \pm 13.57^{\mathrm{c}}$ & $34.20 \pm 3.19^{c}$ & $104.20 \pm 5.15^{b}$ \\
\hline 3 & Corn Silk & $127.25 \pm 9.22^{c}$ & $32.50 \pm 7.33^{c}$ & $70.25 \pm 4.72^{c}$ \\
\hline 4 & Pumpkin seed & $148.50 \pm 6.35^{b}$ & $64.50 \pm 3.32^{a}$ & $51.00 \pm 4.62^{d}$ \\
\hline 5 & Creatine & $177.00 \pm 9.90^{\mathrm{a}}$ & $42.00 \pm 0.81^{b}$ & $133.65 \pm 1.30^{\mathrm{a}}$ \\
\hline
\end{tabular}

All value represented as mean \pm SD.

Means with different superscript are significantly different $(p<0.05)$

Table (6) showed that rats in (+ve) control group had significant decrease in AST level compared to (-ve) control group. Rats fed on pumpkin seeds and creatine had significant increase in AST compared to $(+v e)$ group. Corn silk group recorded significant decrease compared to (+ve) control group, and it was the best result among all tested group. Serum ALT of (+ve) control group was significantly decreased compared to (-ve) control group. Whereas rats fed on corn silk, pumpkin seed and creatine significantly increased compared to (+ve) control group. The best result for ALT at pumpkin seeds group. Results of Ammonia level of (+ve) control group was shown significant increase compared to (-ve) control group. Whereas corn silk group recorded nonsignificant decrease compared to $(+\mathrm{ve})$ control group. But pumpkin seeds and creatine groups showed significant increase in ammonia level compared to (+ve) control group.

Table (6): Effect of Corn Silk, Pumpkin Seed and Creatine on liver functions and ammonia level on rats non exposure to exhaustive time

\begin{tabular}{|c|c|c|c|c|}
\hline \multicolumn{2}{|c|}{ Groups } & $\begin{array}{c}\mathbf{A S T} \\
\mathbf{u} / \mathbf{l}\end{array}$ & $\begin{array}{c}\mathbf{A L T} \\
\mathbf{u} / \mathbf{l}\end{array}$ & $\begin{array}{c}\text { Ammonia } \\
\mu \mathrm{g} / \mathrm{dl}\end{array}$ \\
\hline 1 & $(-v e)$ & $122.00 \pm 2.83^{c}$ & $41.50 \pm 3.00^{b}$ & $73.00 \pm 10.61^{d}$ \\
\hline 2 & (+ve) & $110.75 \pm 25.64^{d}$ & $33.00 \pm 3.16^{d}$ & $93.50 \pm 2.38^{c}$ \\
\hline 3 & corn Silk & $99.82 \pm 4.01^{\mathrm{e}}$ & $42.40 \pm 5.3^{b}$ & $91.60 \pm 2.07^{c}$ \\
\hline 4 & pumpkin & $137.75 \pm 3.86^{b}$ & $36.50 \pm 1.73^{c}$ & $125.05 \pm 3.59^{a}$ \\
\hline 5 & Creatine & $147.00 \pm 7.81^{\mathrm{a}}$ & $45.20 \pm 3.96^{a}$ & $109.84 \pm 3.40^{b}$ \\
\hline
\end{tabular}

All value represented as mean \pm SD.

Means with different superscript are significantly different $(p<0.05)$

Table (7) showed the effect of corn silk, pumpkin seeds, and creatine on, glucose, $\mathrm{CK}$, and $\mathrm{LDH}$ level in male rats which exposure to exhaustive test. The result indicated that glucose level at (+ve) control 
group was significantly increased compared to (-ve) control group. Corn silk group and pumpkin group recorded significant decreased in glucose level compared to (+ve) group, however creatine group recorded significant increase in glucose compared to (+ve) control group. The best result was recorded at corn silk group. Data of creatine kinase revealed that (+ve) control group non-significantly decreased compared with (-ve) control group. The finding indicated that corn silk group, pumpkin seed, and creatine supplementation caused significant increase CK compared with (+ve) control group, the best result among all tested groups was creatine group. LDH level in (+ve) control group shown significant decrease compared to (-ve) control group, but corn silk group, pumpkin seed, and creatine recorded significant decreased compared to (-ve) control group. The best result was corn silk group.

Table (7): Effect of Corn Silk, Pumpkin Seed and Creatine on Glucose, CK and LDH level on rats exposure to exhaustive time

\begin{tabular}{|c|c|c|c|c|}
\hline \multicolumn{2}{|c|}{$\begin{array}{ll} & \text { Parameters } \\
\text { Groups } & \end{array}$} & $\begin{array}{l}\text { Glucose } \\
\mathrm{mg} / \mathrm{dl}\end{array}$ & $\begin{array}{l}\text { CK } \\
\mathbf{u} / \mathbf{l}\end{array}$ & $\begin{array}{c}\text { LDH } \\
\text { u/l }\end{array}$ \\
\hline 1 & (-ve) & $106.01 \pm 5.42^{\mathrm{c}}$ & $24.50 \pm 5.74^{d}$ & $2207.75 \pm 84.16^{\mathrm{a}}$ \\
\hline 3 & (+ve) & $115.02 \pm 11.14^{b}$ & $18.20 \pm 3.96^{d}$ & $1416.40 \pm 91.50^{b}$ \\
\hline 5 & Corn Silk & $96.50 \pm 01.91^{c}$ & $676.25 \pm 18.89^{b}$ & $787.25 \pm 3.77^{\mathrm{e}}$ \\
\hline 6 & Pumpkin seed & $97.00 \pm 03.83^{\mathrm{c}}$ & $1185.00 \pm 84.67^{a}$ & $965.00 \pm 19.51^{d}$ \\
\hline 9 & Creatine & $165.05 \pm 14.14^{\mathrm{a}}$ & $45.65 \pm 2.36^{c}$ & $1301.50 \pm 52.80^{\mathrm{c}}$ \\
\hline
\end{tabular}

All value represented as mean $\pm \mathrm{SD}$.

Means with different superscript are significantly different $(p<0.05)$.

Table (8) showed the effect of corn silk, pumpkin seeds, and creatine on, glucose, $\mathrm{CK}$, and LDH level in male rats which non exposure to exhaustive test according to the experimental training treadmill protocol. The results indicate that (+ve) control group which fed on basal diet and non-exposure to exhaustive time had significant increase in glucose level compared to (-ve) control group. Corn silk and creatine group recorded non-significant increase in glucose level compared with (+ve) control group. However pumpkin seed group shown significant increase compared with (+ve) control group, and also pumpkin seed group considered as the best group among all tested group. Concerning CK concentration in serum, the data indicated that rats in $(+v e)$ control group had non-significant decrease compared with (-ve) control group, furthermore corn silk and pumpkin seed groups shown significant increase in CK level. Creatine group was the best group among all tested group. Results indicate that LDH level was significantly decreased in (+ve) control group when compared with (-ve) control group but in corn silk group, LDH was significantly decreased when compared with (+ve) 
control group. The result pumpkin seeds and creatine groups indicated significant increased values when compared with (+ve) control group.

Table (8 ): Effect of Corn Silk, Pumpkin Seed and Creatine on Glucose, CK and LDH level of rats non-exposure to exhaustive time

\begin{tabular}{|c|c|c|c|c|}
\hline \multicolumn{2}{|c|}{ Groups } & $\begin{array}{l}\text { Glucose } \\
\mathrm{mg} / \mathrm{dl}\end{array}$ & $\begin{array}{l}\text { CK } \\
\mathbf{u} / \mathbf{l}\end{array}$ & $\begin{array}{c}\text { LDH } \\
\mathbf{u} / \mathbf{l}\end{array}$ \\
\hline 1 & $(-\mathrm{ve})$ & $106.01 \pm 5.42^{c}$ & $24.50 \pm 5.74^{c}$ & $2207.75 \pm 84.16^{b}$ \\
\hline 2 & (+ve) & $110.06 \pm 11.17^{b}$ & $17.25 \pm 0.96^{\mathrm{c}}$ & $1465.50 \pm 74.93^{d}$ \\
\hline 3 & corn Silk & $117.60 \pm 01.82^{b}$ & $621.60 \pm 106.78^{a}$ & $922.40 \pm 31.16^{\mathrm{e}}$ \\
\hline 4 & Pumpkin seed & $158.01 \pm 05.77^{a}$ & $50.09 \pm 5.83^{b}$ & $2380.50 \pm 91.22^{a}$ \\
\hline 5 & Creatine & $124.20 \pm 04.82^{b}$ & $20.60 \pm 2.30^{c}$ & $2142.20 \pm 168.50^{c}$ \\
\hline
\end{tabular}

All value represented as mean \pm SD.

Means with different superscript are significantly different $(p<0.05)$.

Table (9), showed the effect of corn silk, pumpkin seeds, and creatine on MDA and GST level in male rats which exposure to exhaustive test according to the experimental training treadmill protocol. Rats in (+ve) control group which fed on basal diet, recorded significant increase in MDA concentration compared to (-ve) control group . While rats in corn silk group, pumpkin seed group, and creatine group had significant decrease when compared to (+ve) control group. Creatine group consider as the best result among all tested group. The results revealed that GST was significantly decreased in (+ve) control group when compared to (-ve) control group, however rats fed on corn silk, pumpkin seed and creatine shown significant increase in GST level when compared with (+ve) control group. The best result recorded in creatine group among all tested group.

Table (9): Effect of Corn Silk, Pumpkin Seed and Creatine on MDA and GST level on rats exposure to exhaustive time

\begin{tabular}{|c|c|c|c|}
\hline \multicolumn{2}{|c|}{$\begin{array}{ll}\text { Groups } & \text { Parameters } \\
\end{array}$} & $\begin{array}{c}\text { MDA } \\
\mathrm{nmol} / \mathrm{ml}\end{array}$ & $\begin{array}{c}\text { GST } \\
\mathbf{u} / \mathbf{l}\end{array}$ \\
\hline 1 & $(-\mathrm{ve})$ & $14.40 \pm 1.09^{b}$ & $122.58 \pm 20.08^{b}$ \\
\hline 2 & (+ve) & $16.13 \pm 0.98^{\mathrm{a}}$ & $95.60 \pm 35.33^{d}$ \\
\hline 3 & Corn Silk & $13.83 \pm 1.00^{b}$ & $167.00 \pm 7.86^{\mathrm{a}}$ \\
\hline 4 & Pumpkin & $13.48 \pm 0.74^{b}$ & $111.03 \pm 17.57^{\mathrm{c}}$ \\
\hline 5 & Creatine & $11.28 \pm 0.84^{c}$ & $114.30 \pm 6.65^{c}$ \\
\hline
\end{tabular}

All value represented as mean \pm SD.

Means with different superscript are significantly different $(p<0.05)$

Table (10) showed the effect of corn silk, pumpkin seeds, and creatine on MAD and GST level in male rats which non-exposure to exhaustive test. Results indicated that MDA level was decreased 
significantly in (+ve) control group when compared with (-ve) control group, while rats fed on corn silk or creatine had non-significant decrease in MDA compared to (+ve) control group, while rats which fed on pumpkin seed recorded a significant reduction compared to (+ve) control group. The result revealed that GST was significantly decreased in (+ve) control group compared to (-ve) control group. Although corn silk group, pumpkin seed group, and creatine group caused a significant increase compared to (+ve) control group. Creatine group was the best result among all tested group.

Table (10): Effect of Corn Silk, Pumpkin Seed and Creatine on MDA and GST level on rats non exposure to exhaustive time

\begin{tabular}{|c|c|c|c|}
\hline \multicolumn{2}{|c|}{$\begin{array}{ll}\text { Groups } & \text { Parameters } \\
\end{array}$} & $\begin{array}{l}\text { MDA } \\
\mathrm{nmol} / \mathrm{ml}\end{array}$ & $\begin{array}{c}\text { GST } \\
\mathbf{u} / \mathbf{l}\end{array}$ \\
\hline 1 & $(-\mathrm{ve})$ & $14.40 \pm 1.09^{a}$ & $122.58 \pm 10.08^{c}$ \\
\hline 2 & (+ve) & $13.83 \pm 1.14^{b}$ & $100.00 \pm 14.49^{d}$ \\
\hline 3 & corn Silk & $12.16 \pm 1.21^{b}$ & $166.80 \pm 13.01^{b}$ \\
\hline 4 & Pumpkin & $10.18 \pm 0.97^{c}$ & $123.56 \pm 13.37^{\mathrm{c}}$ \\
\hline 5 & Creatine & $12.24 \pm 0.13^{b}$ & $189.60 \pm 13.34^{a}$ \\
\hline
\end{tabular}

All value represented as mean \pm SD.

Means with different superscript are significantly different $(p<0.05)$.

Table (11) recorded influences of tested groups on exhaustive treadmill time test of exercised male rats. The result indicated that rats in corn silk group and pumpkin seed recorded 35, 45 min respectively, whereas (+ve) control group which fed on basal diet recorded 20 minute, these results illustrated an increase in exhaustive time test when compared to +ve group.

Table (11): Influence of corn silk, pumpkin seeds, and creatine on exhausting test (min) of male rats

\begin{tabular}{|c|c|c|c|c|c|}
\hline Groups & $(-v e)$ & $(+V e)$ & Corn Silk & Pumpkin seeds & Creatine \\
\hline $\begin{array}{c}\text { Time } \\
\text { (min) }\end{array}$ & - & 20 & 35 & 45 & 25 \\
\hline
\end{tabular}

The result in table (12) indicated that rats in (-ve) control group had sever glycogen content in liver and was recorded the highest level compared to all groups. The rats treated with either corn silk, pumpkin or creatine and exposed to exhaustive treadmill test had nil glycogen content as compared to control groups. While rats had nil, mild, sever glycogen content at non exposure protocol and treated with creatine, pumpkin , corn silk respectively. On the other hand, the glycogen content in gastrocnemius muscle for the rats that exposed to an exhaustive treadmill test was nil, mild, sever for the rats that treated with corn silk, pumpkin, creatine respectively. While non exposure protocol 
caused moderate, sever, moderate increase in glycogen content at the groups fed on corn silk, pumpkin, creatine respectively.

Table (12) Effect of corn silk, pumpkin seeds, and creatine on glycogen content in liver and gastrocnemius muscles exposure and non-exposure to exhaustive treadmill test

\begin{tabular}{|l|c|c|c|c|c|c|}
\hline \multicolumn{1}{|c|}{ organs } & groups & $(-v e)$ & $\begin{array}{c}(+ \text { Ve }) \\
\text { EX }\end{array}$ & $\begin{array}{c}\text { Corn } \\
\text { Silk } \\
\text { EX }\end{array}$ & $\begin{array}{c}\text { Pumpkin } \\
\text { EX }\end{array}$ & $\begin{array}{c}\text { Creatine } \\
\text { EX }\end{array}$ \\
\hline Liver & exhaustive & +++ & + & - & - & - \\
\cline { 2 - 7 } & $\begin{array}{c}\text { Non } \\
\text { exhaustive }\end{array}$ & +++ & ++ & +++ & + & - \\
\hline $\begin{array}{l}\text { Gastrocnemius } \\
\text { muscle }\end{array}$ & exhaustive & + & ++ & - & + & +++ \\
\cline { 2 - 7 } & $\begin{array}{c}\text { Non } \\
\text { exhaustive }\end{array}$ & + & + & ++ & +++ & ++ \\
\hline
\end{tabular}

+++ Sever, ++ Moderate, + Mild, - Nil

\section{DISCUSSION}

Mammalian skeletal muscle is capable of producing a large number of free radicals and it is well recognized that a major source of this free radical production happened during oxygen flux through the mitochondria. Which can increase 100 -fold, potentially resulting in an increased risk of 'oxidative stress', muscle injury and fatigue. However, skeletal muscle is well equipped to deal with this oxidative stress by possessing a number of antioxidant species including both endogenous and exogenous antioxidants. It is only when there are an increased number of free radicals, or a depletion of antioxidant levels that 'redox balance' is disturbed and the cell becomes vulnerable to free radical attack (Spurway and Maclaren, 2007)

In this experimental study, albino male rats were used to examine the oxidative stress effect of corn silk, pumpkin seed, and creatine after exercised by using treadmill reached the exhaustive time test as well as, to determine the changes in body weight, liver enzymes and oxidative stress biomarker.

The palatability of corn silk, pumpkin seed, and creatine powder affected the consumption and partly accounts for the trend in the final body weights of the animals.

Exercise of sufficient intensity and duration can lead to the formation of reactive oxygen and nitrogen species (Fisher-Wellman and Bloomer, 2009), which when produced in amounts that overwhelm the antioxidant defense system may lead to a condition of "oxidative stress". Corn silk and pumpkin total phenolic contents which were seen in Tables 
(1 and 2) may be exhibited antioxidant activity by several mechanisms including a reduction in ischemia-reperfusion-induced oxidative stress (Loffredo et al., 2007and Volek et al., 2002), a reduction in xanthine oxidase activity Spierin et al., 2007)), and a free radical-scavenging activity as shown in Table (2) (Vanella et al., 2000).

Fiber in pumpkin seeds content makes these seeds ideal for weight loss. This dense and heavy snack can keep the body satiated for quite a longer period of time. The fiber takes longer to digest, leaving you full for longer and further keeps you away from bingeing on fattening foods. Other than this, pumpkin seeds is quite a good source of zinc, which can further help in boosting the body's metabolism. A sluggish metabolism can hinder body's weight loss efforts to a great extent. Hence, it is important to keep body's metabolism up and running (Sarine, 2018). These results were consistent with the results of this current research at tables (3 and 4).

In the line with the research results Lee et al., (2016) reported that experimental animals that received high-fat diet along with 100 $\mathrm{mg} / \mathrm{kg}$ of high maysin corn silk extract for 8 weeks showed significant reduction of body weight compared to the high-fat diet only group. Additionally, kidney fat and epididymal fat pad weights significant decreased, demonstrating high maysin corn silk extract had a weightreducing effect by decreasing fat accumulation in the body. Min et al., (2011) reported that administration of $100 \mathrm{mg} / \mathrm{kg} \mathrm{BW}$ and $400 \mathrm{mg} / \mathrm{kg}$ BW of corn silk extract significantly lowered body weight after 2 weeks of intake in mice, which is consistent with the weight-reducing effect.

Results of the present study were in a line with Kreider $\boldsymbol{e t}$ al., (1998) which indicate that $28 \mathrm{~d}$ of creatine supplementation $\left(15.75 \mathrm{~g} \cdot \mathrm{d}^{-1}\right)$ during resistance/agility training promoted significantly greater gains in fat/bone-free mass. These findings support previous reports that creatine supplementation may increase total body weight and/or lean body mass, as seen at tables (3 and 4).

The most sensitive and profitable diagnostic enzymes of the liver are aminotransferases including AST and ALT. Generally, certain amounts of these enzymes are produced by liver cells, yet after liver damage, the liver cells increase the secretion of the enzymes and their plasma levels, whose increased level is a sign of liver damage (Terohid et al., 2015). The incidence of oxidative stress in the body has other negative effects, such as muscle fatigue, early restlessness impaired, decreased immune function, and muscle oxidation (Bloomer and 
Goldfarb, 2004). The results showed that 60 days of training protocol had slightly alteration effect on serum levels of ALT and AST on +ve and corn silk feeding groups exposed to exhaustive test. The lack of alteration is inconsistent with the findings of (Kim et al., 2007 and Ghasemnian et al., 2020). Acute strenuous exercise induces oxidative stress and/or tissue damage in several tissues including skeletal muscle, liver, and kidney (Suzuki et al 2003; Aoi et al., 2004 and Suzuki, 2018). It is well known that antioxidant capacity is increased by acute or chronic exercise (Yada et al., 2020). This research results were in a line with above findings at tables (5 and 6 ) especially corn silk group showed great improvement compared with other treated groups.

Ammonia can cross the blood-brain barrier and has the potential to affect central neurotransmitter levels and central neural fatigue (Hargreaves and Lawrence, 2020). An increase in ammonia concentration occurs predominantly after high-intensity exercise, where ammonia aids in stimulating glycolysis. With increasing fatigue, the level of ammonia biomarker increase, reflecting the physiological status of the athlete (Kantanista et $\boldsymbol{a l}$., 2016).These results agree with the present study findings. As shown in the research results, corn silk play a whiteness role in the ammonia values impairment higher than pumpkin and creatine. The action of corn silk extract on mice was by increasing insulin level and recovering injured beta cells, and not via increasing glycogen or inhibiting gluconeogenesis. The results suggest that in modern pharmacological study, corn silk extract may be used as a hypoglycemic food or medicine for hyperglycemic people (Guo et al., 2009). Pancreatic enzyme synthesis and secretion may change with physical exercise (Minato, 2000). In rats, endurance running training increases pancreatic protein content, pancreatic enzyme activity, and basal amylase secretion (Minato, 1997), this finding was in the same line with the present study of glucose level and agreement with (praphatsorn et al., 2010) which found that high-intensity exercise at $75 \%$ and $90 \%$ VO2max caused an increase of biochemical parameters in liver and pancreas. The levels of exercise also caused histopathology changes in the liver and pancreas.

Seeds from contain bioactive compounds which have antifatigue activity and can elevate exercise performance. The seeds were said to have bioactivities such as hepatoprotection, anti-diabetes, anticancer, and anti-obesity properties (Wang, 2012). According to Bharti et al., (2013), tocopherol isomers $(\alpha, \beta, \gamma$, and $\delta)$ from raw pumpkin seeds has been 
reported to be effective in the alleviation of diabetes through its antioxidant activities. In another studies also on alloxan-induced diabetic rats demonstrate that polysaccharide from pumpkins has hypoglycemic effect (Xiong and Cao, 2001).This polysaccharide $(50 \mathrm{mg} / \mathrm{kg})$ administered orally in alloxan-induced diabetic increase the body weight, reduce water intake, and blood glucose levels of diabetic mice group compared with diabetic control group (Perez Gutierrez, 2016). Furthermore, the administration of fruit powder for a month in diabetic rats significantly reduced C-reactive protein (CRP), cholesterol, glucose, Triglycerides while insulin was increased in diabetic rats (Sedigheh et al ., 2011). Gualano et al., (2010) showed that creatine supplementation combined with exercise alleviated glycemic conditions in T2DM.

Release of CK from muscle cells during exercise corresponds to the degree of permeability of cell membranes and their damage resulting, among other things, from an increase in the amount of free radicals formed during physical activity, leading to the peroxidation of cell membrane lipids (Banfi et al., 2012). After muscle-damaging exercise, the enzyme CK leaks from the muscle into the circulation. It is typical for athletes to have elevated $\mathrm{CK}$ during training, with reference ranges of $82-1,083 \mathrm{u} / \mathrm{l}$ in male and $47-513 \mathrm{u} / \mathrm{l}$ in female athletes suggested as athletic norms (Mougios, 2007).

In the present study table ( 7 ) showed increasing in creatine kinase in pumpkin seed group among others groups, those results in the similar line with ( AL-Zuhair et al ., 1997) which suggested that pumpkin seeds oil was recorded ameliorated in creatine kinase levels ,while creatine group recoded lowest creatine kinase level , this finding in the same line with (Bassit $\boldsymbol{e t}$ al., 2010) observed a decrease in several markers of muscle damage (creatine kinase, lactate dehydrogenase, aldolase, glutamic oxaloacetic acid transaminase and glutamic pyruvic acid transaminase) in 4 athletes after an iron man competition who supplemented with $20 \mathrm{~g} / \mathrm{d}$ plus $50 \mathrm{~g}$ maltodextrin during a $5 \mathrm{~d}$ period prior to the competition.

During exercise, when muscles exhaust the oxygen, pyruvate gets catalyzed into lactic acid by the lactate dehydrogenase enzyme. In erythrocytes also pyruvate is not further metabolized due to the absence of mitochondria but remains within the cytoplasm, finally converting to lactate. In this reaction, NADH oxidizes to NAD+. The availability of high intracellular concentrations of NAD is necessary to carry out the preparatory phase of glycolysis. The net ATP production 
of anaerobic glycolysis is only 2 ATP per glucose molecule as compared to oxidative phosphorylation, which produces 36 ATP per glucose molecule. LDH can also catalyze the dehydrogenation of 2hydroxybutyrate, but it is the less preferred substrate for LDH than lactate (Adeva-Andany et al., 2014), our result in table ( 8) showing increasing in LDH in creatine group which prove the previous hypothesis.

Table (9 ) showing decreasing in MDA level with corn silk, pumpkin seed, and creatine groups compare with positive control group which reflect the great amount of antioxidant compounds like phenolic acids, polyphenols and flavonoids scavenge free radicals such as peroxide, hydroperoxide or lipid peroxyl and thus inhibit the oxidative mechanisms that lead to degenerative diseases (Hu and Deng, 2011),this met agreement with ( Bouzid $\boldsymbol{e}$ al., 2015) who found that MDA level was higher during the recovery period in the high fitness level as compared with the others groups,which concluded that both low and high physical fitness levels help maintain better antioxidant defenses in older adults. However, a higher physical fitness level, rather than a lower physical fitness level, could increase lipid peroxidation. MDA is one the most popular oxidative stress markers, and due to its toxicity.

Biomarkers to evaluate the antioxidant capacity include glutathione, glutathione peroxidase, catalase, and the total antioxidant capacity (Finsterer, 2012) GSTs are postulated as important detoxifying enzymes that catalyse reduced glutathione-dependent reactions involved in cellular protection against OS and toxic chemicals (Liavanera et al., 2020), the present study GST results agree with the previous study and (Ghahremanloo et al ., 2017) which demonstrate that Pumpkin ameliorated oxidative stress and dyslipidemia in obese rats, leading to decrease cardiovascular disease risk in obesity. However, some studies showed different flavonoid synergists as most effective in hepatoprotection. Moreover, it has been reported that corn silk effectively increases antioxidant enzyme levels such as sodium dismutase and glutathione peroxidase (Hu and Deng, 2011).

The data in table (11) explained the major findings of the present study were that rats fed on pumpkin seeds and exposure to exhaustive test recorded $(45 \mathrm{~min})$ the longest period among all tested groups, this reflect Pumpkin seed and seed oil are a rich natural source of phytosterols, proteins, polyunsaturated fatty acids, antioxidant vitamins, carotenoids and tocopherols, and various elements, due to these 
components are attributed providing many health benefits, (Perez Gutierrez, 2016). High energy consumption during intense exercise may cause an imbalance between the oxidation and anti-oxidation systems, resulting in an increase in ROS and a reduction in antioxidant activities. These behaviors lead to enhanced ROS production. Oxidative stress is involved in both chronic fatigue and other fatigue related disorders (Barclay and Hansel, 1991) Extreme physical stress could lead to excessive generation of ROS in the skeletal muscle which, in turn, results in peripheral fatigue (Allen et al., 2008).

Glycogen is an important energy material that enables movement and provides adequate energy for muscle contraction. Energy use reduces glycogen; meanwhile, an increase in hepatic glycogen can improve exercise endurance (Anand, 2012)

The our histopathological examination to determine the glycogen contents in liver and muscles variation between all rat groups which exposure to exhaustive treadmill test indicated that rats in creatine group were depleted glycogen content from liver but muscle stored it in sever amount, unlike the rats in corn silk group were depleted glycogen content from liver and muscle our result have supported from (Ivy et al., 2002) who tested the hypothesis that a carbohydrate-protein supplement would be more effective in the replenishment of muscle glycogen after exercise compared with a carbohydrate supplement of equal carbohydrate content or caloric equivalency when supplementing immediately and 2- hours post exercise. The results indicate that the co-ingestion of protein with carbohydrate will increase the efficiency of muscle glycogen storage when supplementing at intervals greater than 1-hour apart, or when the amount of carbohydrate ingested is below the threshold for maximal glycogen synthesis. These results have important implications for athletes who wish to limit their carbohydrate intake in an effort to control body weight and for those athletes who participate in sports that have very short recovery periods during competition such as basketball, ice hockey and soccer.

Steensberg et al., (2002) suggest that pre-exercise glycogen content may Influence glucose uptake during subsequent exercise. However, this is only the case when delivery of substrates and hormones remains constant. When delivery of substrates and hormones is altered, the potential effect of glycogen on glucose uptake is negated. (Evans $\boldsymbol{e t}$ al., 2019) suggest that the type, duration, and intensity of the resistance 
training program are important factors in determining the effects of resistance training on skeletal muscle glycogen content.

On the other hand at the present study, the supplemented groups which not exposure to exhaustive treadmill test preserves the glycogen content either in liver or muscle, and that met agreement with hypothesis that Decreased use of muscle causes it to become much less metabolically efficient; unfortunately, this de adaptation becomes apparent within a few days after cessation of exercise. Other factors induced by endurance training include changes in cardiac output, increases in capillary density, and increases in glycogen stores (Baynes and Dominiczak ,2019).

Findings of these study prove that corn silk and pumpkin seeds were a good source of flavonoid which help to scavenge the oxidative stress substances, creatine recorded the largest glycogen quantity in gastrocnemius muscles among supplemented groups, but it is causing an elevation ammonia, and AST levels on the groups which exposure to exhaustive time test, so more studies for creatine efficacy on skeletal muscle is recommended. Moreover, it could be recommended that corn silk and pumpkin seeds have the ability to eliminate physical fatigue and prolong the training period without fatigue.

\section{REFERENCES}

Adeva-Andany, M. ; M. López-Ojén ; R. Funcasta-Calderón ; E. Ameneiros-Rodríguez and C. Donapetry-García (2014): Comprehensive review on lactate metabolism in human health . Mitochondrion. Jul; 17:76-100.

Allen, D.G. ; G.D. Lamb and H. Westerblad (2008):Skeletal muscle fatigue: cellular mechanisms. Physiol Rev; 88(1):287-332.

Al-Zuhair, H. ; A.A. Abdel-Fattah and H.A. Abdel-Latif (1997) :Efficacy of Simvastatin and Pumpkinseed Oil in The Management of Dietary-induced Hypercholesterolemia, Pharmacol.Res., 35(5): 403-408.

Anand, T. ; G. Phani Kumar and M.D. Pandareesh (2012): Effect of bacoside extract from Bacopa monniera on physical fatigue induced by forced swimming. Phytother Res.; 26(4):587-593.

Andritsos, N. ; P. Dalampakis and N. Kolios (2003): Use of geothermal energy for tomto drying. Bulletin, 70(4): 9-13.

Aoi, W. ; Y. Naito ; Y. Takanami ; Y. Kawai ; K. Sakuma ; H. Ichikawa and N. Yoshida (2004): Oxidative stress and 
delayed-onset muscle damage after exercise. Free Radic. Biol. Med., 37: 480-487.

Araújo, M. ; L. Moura ; J.R. Vieira ; C. Marcelo ; R. Dalia ; A. Sponton ; C. Ribeiro and M. Alice (2013): Creatine supplementation and Oxidative stress in rat liver. Journal of the International Society of Sports Nutrition., 10:54.

Banchroft, J.D. ; A. Stevens, and D.R. Turner (1996): Theory and practice of histological techniques.4th ed. Churchill Livingstone, New York, London, San Francisco, Tokyo.

Banfi, G. ; A. Colombini; G. Lombardi and A. Lubkowska (2012): Metabolic markers in sports medicine. Advances in Clinical Chemistry.; 56: 1-54.

Barclay, J.K. and M. Hansel (1991): Free radicals may contribute to oxidative skeletal muscle fatigue. Can J Physiol Pharmacol.; 69(2):279-284.

Bassit, R.A. ; C.H. Pinheiro ; K.F. Vitzel ; A.J. Sproesser ; L.R. Silveira and R. Curi (2010): Effect of short-term creatine supplementation on markers of skeletal muscle damage after strenuous contractile activity. Eur J Appl Physiol, 108:945-955.

Baynes , J.W. and M.H. Dominiczak (2019):Medical biochemistry .EL SEVIER 5TH ed .p559,562.

Bharti, S.K. ; A. Kumar ; N.K. Sharma ; B.O. Prakash and S.K. Jaiswal (2013): Tocopherol from seeds of Cucurbita pepo against diabetes: Validation by in vivo experiments supported by computational docking. J Formosan Med Assoc., 112: 676-690.

Brand-Williams, W. ; M.E. Cuvelier and C. Berset (1995): Use of a freeradical method to evaluate antioxidant activity. LWT Food Sci. Techno., 28: 25-30.

Bloomer, R.J. and A.H. Goldfarb (2004): Anaerobic exercise and oxidative stress: a review. Can J Appl Physiol.; 29(3):245-63. doi: 10.1139/h04-017.

Bouzid, M.A. ; O. Hammouda ; R. Matran and S. Robin (2015): influence of physical fitness on antioxidant activity and malondialdehyde level in healthy older adults. Appl Physiol Nutr Metab; 40(6):582-9.

Ching, W. ; W. Chun ; H. Chuang ; D.T. Wei ; Z. Min ; W. Li ; F. Chen and C.H. Chang (2015): Effect of Curcumin Supplementation on Physiological Fatigue and Physical Performance in Mice. Nutrients., 7: 905-921. 
Davis, M. ; A. Murphy ; M.D. Carmichael and B. Davis (2009): Quercetin increases brain and muscle mitochondrial biogenesis and exercise tolerance. Am J Physiol Regul Integr Comp Physiol., 296:1071-1077.

Ebrahimzadeh, M.A.; F. Pourmorad and S. Hafezi (2009): Antioxidant activities of Iranian corn silk. Turkish J Biol., 32:43-49.

Evans, P.L. ; S .L. McMillin and L.K . Weyrauch (2019): Regulation of Skeletal Muscle Glucose Transport and Glucose Metabolism by Exercise Training. Nutrients; 11: 24-32.

Finsterer, J.(2012): Biomarkers of peripheral muscle fatigue during exercise. BMC Musculoskelet Disord ; 13: 218.

Fisher-Wellman, K. and R.J. Bloomer (2009): Acute exercise and oxidative stress: a 30 year history. Dyn Med; 8:1.

Gama, M.S. (2011): Efeitos da creatina sobre desempenho aeróbio: uma revisão sistemática. Revista Brasileira de Nutrição Esportiva., 5:182-190.

Ghahremanloo, A. ; R. Hajipour ; M. Hammati and M. Moossavi (2017): the beneficial effect of pumpkin extract on atherogenic lipid ,insulin resistance and oxidative stress statues in high-fat diet -induced obese rats. Journal of Complementary and Integrative Medicine; 15: (2).

Ghasemnian, A. ; Z. Iddehloei ; A. Rahmani and M. Usefpour (2020): Effects of ginger along with exercise training on serum levels of ALT and AST liver enzymes and malondialdehyde and the activity of liver tissue superoxide dismutase in male Wistar rats Journal of Shahrekord University of Medical Sciences.; 22 (2): 67-73.

Gualano, B. ; V. Painneli ; H. Roschel ; G.A. Giannini and M. Neves (2010): creatine in type 2 diabetes: A Randomized, DoubleBlind, Placebo-Controlled Trial. Journal of the medicine and Science in Sports and Exercise;43(5):770-8.

Guo, J. ; T. Liu ; L. Han and Y. Liu (2009): The effects of cornsilk on glycaemic metabolism, Pubmed, Nutr Metlab London

Habig, W. ; M. Pabst and W.J. Jakoby (1974): Glutathione Stransferase A. A novel kinetic mechanism in which the major reaction pathway depends on substrate concentration. J. Biol. Chem., 249: (22): 7140-7147. 
Hargreaves, M. and L.S. Lawrence (2020): Skeletal muscle energy metabolism during Exercise. Nature Metabolism; 2: 817-828.

Hu, Q.L. and Z.H. Deng (2011): Protective effects of flavonoids from corn silk on oxidative stress induced by exhaustive exercise in mice. African journal of biotechnology .10(16).

Hu, Q.L. ; L.J. Zhang ; Y.N. Li ; Y.J. Ding, and F.L. Li (2010): Purification and anti-fatigue activity of flavonoids from corn silk. International Journal of Physical Sciences; 5(4): 321-326.

Kantanista, A. ; K. Kusy and K. Dopierala (2016): Blood lactate, ammonia and kinematic indices duringa speed-endurance training session in elite sprinters. TRENDS in Sport Sciences; 2(23): 73-79.

Kim, H.J. ; Y.H. Lee and C.K. Kim (2007): Biomarkers of muscle and cartilage damage and inflammation during a $200 \mathrm{~km}$ run. Eur J Appl Physiol.;99(4):443-7.

Kreider, R.B. ; M. Ferreira and M. Wilson (1998): Effects of creatine supplementation on body composition, strength, and sprint performance. Medicine \& Science in Sports \& Exercise; 30 (1): 73-82.

Lee, E.Y. ; S.K. Lim ; H.K. Jung ; M.K. Hwan; A.H. Wha and W.K. Kyoung (2016): High maysin corn silk extract reduces body weight and fat deposition in C57BL/6J mice fed high-fat diets. Nutrition Research and Practice; 10(6):575-582.

Lee, E.C. ; M.S. Fragala ; S.A. Kavouras ; R.M. Queen ; J.L. Pryor and D.J. Casa (2017): Biomarkers in sports and exercise: tracking health, performance, and recovery in athletes. J Strength Cond Res., 31(10): 2920-2937

Liavanera, M. ; A. Delgado-bermudez and S. Olives (2020): Glutathione S-Transferase play acrucial role in mitochondrial function ,plasma membrane stability and oxidative regulation of mammalian sperm. Antioxidants (Basel), 24; 9(2):100.

Loffredo, L. ; A. Marcoccia ; P. Pignatelli and P. Andreozzi (2007): Oxidative-stress-mediated arterial dysfunction in patients with peripheral arterial disease. Eur Heart J.; 28:608-612.

Ivy, J.L. ; H.W. Goforth ; B.D. Damon ; T.R. McCauley ; E.C. Parsons and T.B. Price (2002): Early post exercise muscle glycogen recovery is enhanced with a carbohydrate-protein supplement. Journal of Applied Physiology, 93: 1337-1344. 
Minato, K.(1997): The Effect of endurance training on pancreatic enzyme activity in rats. Eur J Appl Physiol Occup Physiol; 76: 491-4.

Minato, K. (2000): The effect of chronic exercise on the rat Pancreas. Int J Pancreatol ; 27:151-6.

Min, O.J. ; B.R. Sharma ; C.M. Park and D.Y. Rhyu (2011): Effect of myadis stigma water extract on adipogenesis and blood glucose in 3T3-L1 adipocytes and db/db mice. Korean J Pharmacogn; 42:201-8.

Mougios, V. (2007): Reference intervals for serum creatine kinase in athletes. Br J Sports Med 41: 674-678,

Ohkawa, H. ; W. Ohishi and K. Yagi (1979): Assay for lipid peroxides in animal tissues by thiobarbituric acid reaction. Anal Biochem., 95(2):351-8.

Patel, S .(2013): Pumpkin (Cucurbita sp.) seeds as nutraceutic: a review on status quo and scopes. Mediterr J Nutr Metab., 6 (3): 183-189.

Perez Gutierrez, R.M (2016): Review of Cucurbita pepo (Pumpkin) its Phytochemistry and Pharmacology. Med Chem., 6: 012-021.

Praphatsorn, P. ; D. Thong-Ngama ; O. Kulaputanaa and N. Klaikeawb (2010): Effects of intense exercise on biochemical and histological changes in rat liver and pancreas. Asian Biomedicine; 4. (4): 619-625.

Sarine, D. (2018): Pumpkin Seeds For Weight Loss: Switch Over To This Healthy Snack To Lose Weight Healing Foods. DK Publishing House.

Schumann, G. ; R. Bonora ; F. Ceriotti et al (2002): Gerhard Weidemann14 and Lothar Siekmann15IFCC Primary Reference Procedures for the Measurement of Catalytic Activity Concentrations of Enzymes at $37^{\circ} \mathrm{C}$. Clin Chem Lab Med; 40(7):725-733

Sedigheh, A. ; M.S. Jamal ; S. Mahbubeh ; K. Sornayeh ; R. Mahmoud, et al. (2011): Hypoglycaemic and hypolipidemic effects of pumpkin (Cucurbita pepo L.) on alloxan-induced diabetic rats. Afr J Pharm Pharmacol., 5: 2620-2626.

Sendecor, G. and W. Cochran (1986): Statistical methods 7 th ed,iowa state university press,Ames,USA,90.

Sherwin, J.E. (1984): Liver function. In:kaplan LA, PESCE AJ, eds. Clinical chemistry, theory,analysis, and correlation. St Louis: Mosby: 420- 438.

Spierin, B.A. ; W.J. Kraemer; J.L. Vingren and D.L. Hatfield (2007): Responses of criterion variables to different supplemental doses of L-carnitine L-tartrate.J Strength Cond Res; 21:259. 
Spurway, N. and D. Maclaren (2007): Nutrition and Sport. Elsevier, 154.

Steensberg, A. ; G. van Hall ; C. Keller and T. Osada (2002): Muscle glycogen content and glucose uptake during exercise in humans: influence of prior exercise and dietary manipulation. Journal of Physiology, 541(1): 273-281.

Suzuki, K. (2018): Involvement of neutrophils in exercise-induced muscle damage. Gen. Intern. Med. Clin. Innov, 3: 1-8.

Suzuki, K. ; S. Nakaji ; M. Yamada ; Q. Liu ; S. Kurakake ; N. Okamura and T. Kumae (2003): Impact of a competitive marathon race on systemic cytokine and neutrophil responses. Med. Sci. Sports Exerc., 35: 348-355.

Tietz, N.W (1976): Fundamentals of clinical chemistry .2nd ed W.B Saunders Philadelphia.

Terohid, S. ; M. Mirazi and A. Sarihi (2015): Study of hepatoprotective effect of Malva neglecta L. hydroethanolic leaf extract in male rat Induced with carbon tetrachloride. Journal of Cell \& Tissue.; 6(1):31-42.

Trinder, P. (1969): Enzymatic determination of glucose in blood serum. Annals of Clinical Biochemistry, 6: 24.

Vassault, A. ; D. Grafmeyer ; C. Naudin ; G. Dumont ; M. Bailly and J. Henny (1986): Protocole de validation de techniques. Ann.Biol. Clin., 44: 686.

Volek, J.S. ; W.J. Kraemer ; M.R. Rubin ; A.L. Gómez ; N.A. Ratamess and P. Gaynor (2002): L-Carnitine L-tartrate supplementation favorably affects markers of recovery from exercise stress. Am J Physiol Endocrinol Metab; 282:E474-482.

Wang, S.Y. ; W.C. Huang ; C.C. Liu ; M.F. Wang ; C.S. Ho and W.P. Huang (2012): Pumpkin (Cucurbita moschata) fruit extract improves physical fatigue and exercise performance in mice. Molecules., 17:11864-11876.

Weissman, M. and B. Klein (1958): Evaluation of glucose determination in untreated serum samples. Clin Chem., 4(27):420-422.

Xiong, X. and J. Cao (2001): Study of extraction and isolation of effective pumpkin polysaccharide component and its reducing glycemia function. Chinese J Modern Application Pharm., 18: 662-664.

Yada, K. ; L.R. Arwyn ; N. Oginome and K. Suzuki (2020): Effect of Acacia Polyphenol Supplementation on Exercise-Induced Oxidative Stress in Mice Liver and Skeletal Muscle. J Antioxidants mdpi, 9, 29; doi:10.3390/antiox9010029. 
تاثير حرير الأرة ،بذور اليقطين و الكرياتين على الاجهاد التاكسدى لفئران

الأكور المدربة

نعيم محمد رابح ، محمد حمدى حجاج ، اسماء زايد محمد

قسم التذذية وعلوم الاطعمة - كلية الاقتصاد المنزلى -جامعة حلوان - القاهرة -جمهورية مصر العربية

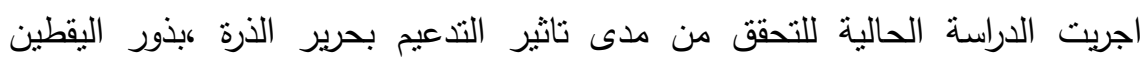

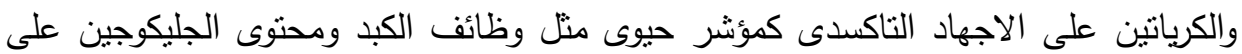

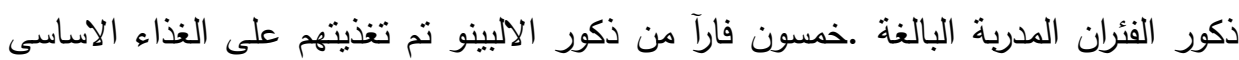

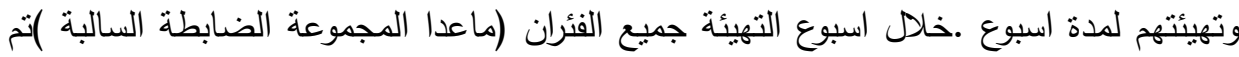

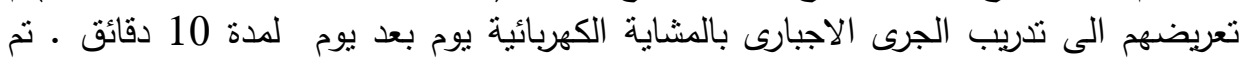
تقسيم الفئران الى مجموعتين رئيسيتين ،المجموعة الرئيسية الاولى (عدد 10 فئران ) تم تغذيتهر بالئه على الغذاء الاساسى فقط وصنفت كمجموعة ضابطة سالبة .المجموعة الرئيسية الثانية (الفئران

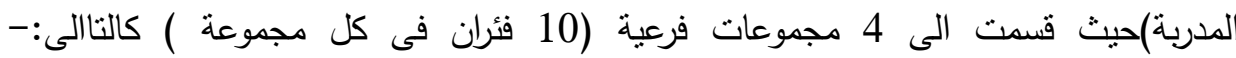

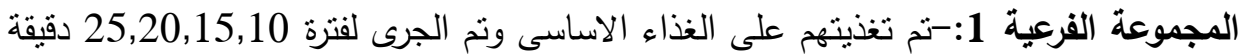

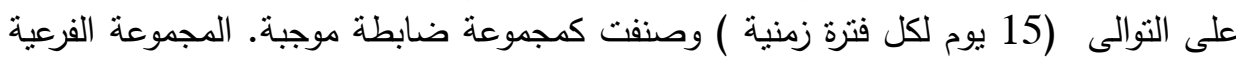

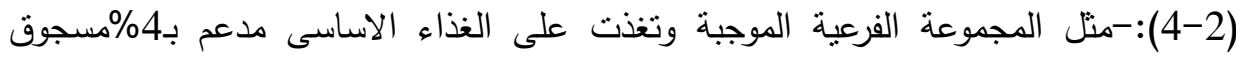

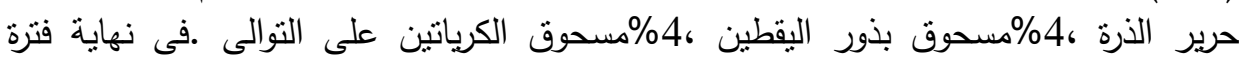
التجربة (60 يوم)5 فئران من كل مجموعة فرعية تم تعريضهم الى اختبار الاجهاد المستئفي

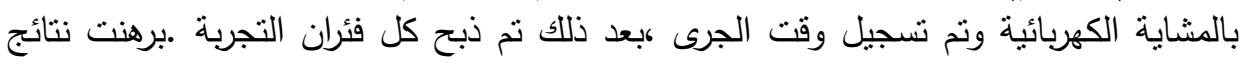

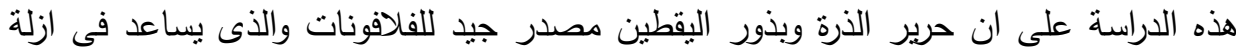

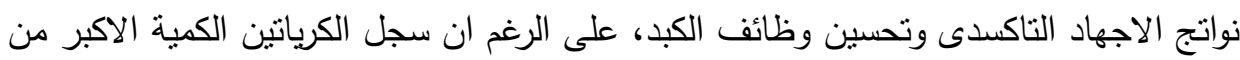

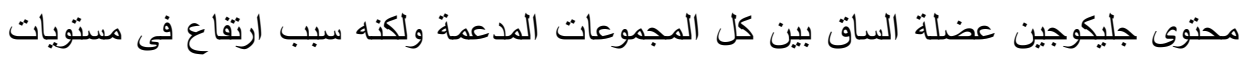
الامونيا و AST فى المجموعة التى تعرضت الى اختبار وقت الاجهاد المستتفذ ـ بمكن التوصية بحرير الذرة وبذور اليقطين لقدرته على تقليل الارهاق البدنى وإطالة فترة التتمرين دون

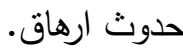

الكلمات المفتاحية:- حرير الذرة ، بذور اليقطين، مكملات الكرياتين ،كرياتين كاينيز ، لاكتات

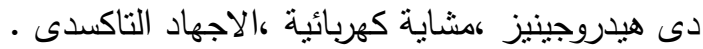

